\title{
Characterization of Wood-based Industrial Biorefinery Lignosulfonates and Supercritical Water Hydrolysis Lignin
}

\author{
Venla Hemmilä ${ }^{1}\left[\mathbb{D} \cdot\right.$ Reza Hosseinpourpia ${ }^{1} \cdot$ Stergios Adamopoulos ${ }^{1} \cdot$ Arantxa Eceiza $^{2}$
}

Received: 29 March 2019 / Accepted: 11 November 2019 / Published online: 14 November 2019

(c) The Author(s) 2019

\begin{abstract}
Understanding the properties of any particular biorefinery or pulping residue lignin is crucial when choosing the right lignin for the right end use. In this paper, three different residual lignin types [supercritical water hydrolysis lignin (SCWH), ammonium lignosulfonate (A-LS), and sodium lignosulfonate (S-LS)] were evaluated for their chemical structure, thermal properties and water vapor adsorption behavior. SCWH lignin was found to have a high amount of phenolic hydroxyl groups and the highest amount of $\beta-O-4$ linkages. Combined with a low ash content, it shows potential to be used for conversion into aromatic or platform chemicals. A-LS and S-LS had more aliphatic hydroxyl groups, aliphatic double bonds and $\mathrm{C}=\mathrm{O}$ structures. All lignins had available $\mathrm{C}_{3} / \mathrm{C}_{5}$ positions, which can increase reactivity towards adhesive precursors. The glass transition temperature $\left(\mathrm{T}_{\mathrm{g}}\right)$ data indicated that the SCWH and S-LS lignin types can be suitable for production of carbon fibers. Lignosulfonates exhibited considerable higher water vapor adsorption as compared to the SCWH lignin. In conclusion, this study demonstrated that the SCWH differed greatly from the lignosulfonates in purity, chemical structure, thermal stability and water sorption behavior. SCWH lignin showed great potential as raw material for aromatic compounds, carbon fibers, adhesives or polymers. Lignosulfonates are less suited for conversion into chemicals or carbon fibers, but due to the high amount of aliphatic hydroxyl groups, they can potentially be modified or used as adhesives, dispersants, or reinforcement material in polymers. For most value-adding applications, energy-intensive purification of the lignosulfonates would be required.
\end{abstract}

\section{Graphic Abstract}
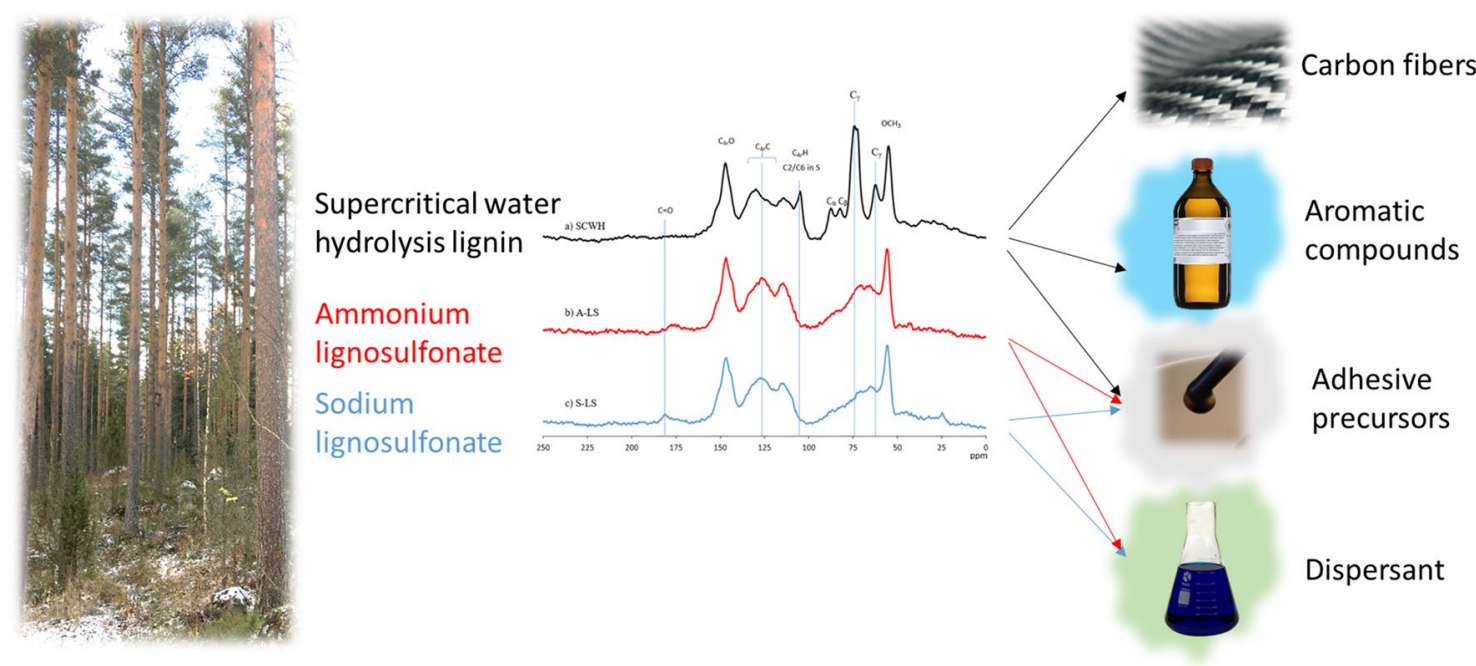

Keywords Ammonium lignosulfonate $\cdot$ Sodium lignosulfonate $\cdot$ Hydrolysis lignin $\cdot$ Phenolics $\cdot$ Aromatics

Extended author information available on the last page of the article 


\section{Statement of Novelty}

Supercritical water hydrolysis (SCWH) lignin is novel type of lignin from a biorefinery process that only uses water. Because of this, SCWH lignin is closer to its natural state than other industrial residual lignin types. In this work, the SCWH biorefinery lignin residue has been compared to another less common biorefinery residual lignin type: lignosulfonates. Chemical, thermal and vapor sorption characterization of the residual lignin types have been done in order to find optimal value-added application.

\section{Introduction}

Utilization of lignocellulosic raw materials provides an excellent alternative to petroleum based ones, as they are sustainable, do not compete with food sources, and can have a positive impact on reduction of global greenhouse emissions. Value-adding applications are desired especially for lignins from biorefinery processes, due to the increase in conversion of biomass into transportation fuels that will generate substantially more lignin than necessary to power the operation [1].

Valorization of lignin, however, is challenging due to its amorphous and robust structure [2]. Besides the origin of the lignin, the extraction method plays a key role in the final lignin structure [2-4]. Like other lignin types obtained from chemical pulping processes (e.g. kraft lignin, and the less common soda and organosolv lignins), the lignins from the sulfite process (lignosulfonates) contain low amount of $\beta-O-4$ linkages (less than $10 \%$ ) and high amounts of $\mathrm{C}-\mathrm{C}$ bonds $[3,5]$. However, unlike kraft and hydrolysis lignin, lignosulfonates are water-soluble over almost the entire pH-range [3] and are currently used as dispersants for various applications [6]. They provide up to $90 \%$ of commercial lignin and have annual worldwide production of approximately 1.8 million tons [7]. Characterization studies have shown that lignosulfonates have high molecular weight and contain high amounts of sulfonate groups. Both of these properties are crucial in determining their dispersing efficiency and use for other applications [8-11]. Controlling the molecular weight of lignosulfonates can be done by various techniques, such as separation, depolymerization, and chemical modification [12]. Characterization studies have led to the partial elucidation of the structure of lignosulfonates, however much of their overall global structure and shape is still not well known.

Sulfur used in both kraft and sulfite pulping processes, however, is an environmental concern [2]. Because of this, more environmentally friendly solvents are wished for, especially as they enable co-production of a sugar stream for fermentation. Organosolv and steam explosion processes are more suitable than sulfur-based pulping processes in that respect, but the most environmentally friendly solvent is water. Water above its critical point can act as the reactant or catalyst for breaking down biomass $[13,14]$. Supercritical water can dissolve and hydrolyze lignin for potential production of phenolic chemicals or for upgrading lignin for fuels [15]. The temperature and reaction time greatly affects the depolymerization pathway and rate of the hydrolysis [16]. Like the chemical pulping processes, the main reactions in supercritical water hydrolysis are cleavage of the $\beta-O-4$ linkages and propane side chains and demethoxylation $[17,18]$.

Annually, more than 50 million tons of lignin worldwide are used as a combustion fuel in pulp mills while a very small portion of lignin (around $2 \mathrm{wt} \%$ ) is used commercially, mainly in low-value applications $[19,20]$. There are three pathways to create value-added products from lignin: (i) Due to the large amounts of aromatic structures present in lignin, it can be depolymerized into aromatic or platform chemicals. Fragmentation of lignin into smaller aromatic compounds offers a significant market potential, but it is less developed than the use of lignin as a macromolecule [21]. (ii) Lignin as an unchanged macromolecule is used as additive or polymer blend [2]. (iii) Lignin consists of about $50-60 \%$ of carbon, and can thus be directly used as a precursor for carbon materials such as activated carbons and carbon fibers [22].

Aromatic compounds such as benzene, toluene, xylenes, phenols and vanilin can be depolymerized from lignin by combining solvotic extraction with reductive depolymerization [23]. Low molecular weight and high amount of reactive groups (e.g. carbonyl groups) have a positive impact on the depolymerization process [24]. The amount of $\beta-O-4$ linkages in the lignin also correlates closely with the yields of syringyl, guaiacyl and $p$-hydroxyphenyl aromatic products [25]. However, especially for lignins from chemical processes, the amount of $\beta-O-4$ linkages is typically so low, that mild cleavage methods (oxidative, reductive and redox-neutral methods) do not have a major effect [3]. If depolymerization is desired, conditions capable of breaking the $\mathrm{C}-\mathrm{C}$ bonds, such as pyrolysis, hydrogenolysis and treatment with supercritical water, need to be applied [3]. These processes are often less selective and lead to highly complex chemical compositions that need to be further catalytically converted to the desired end-products [26]. Lignin gasification, for example, depolymerizes the lignin into syngas that can be used to generate electricity, pure hydrogen, or other chemicals $[2,3]$.

In adhesive, additive and polymer applications, lignin is used in its macromolecular state [2]. The chemical structure and thermal behavior of lignin determines its suitability 
towards these different applications. The most developed adhesive application for lignin is replacement of phenols in phenol-formaldehyde adhesives [27]. Besides active sites, the amount of aliphatic and phenolic hydroxyl groups increase the reactivity of lignin towards synthetic adhesive precursors such as aldehydes, tannins, phenols and isocyanates $[28,29]$. The number of available reactive groups (e.g. $\mathrm{COOH}$, phenolic and aliphatic hydroxyl groups) also determines the reinforcement effect of lignin in different polymer blends. Grafting of lignin is often required to make it compatible with polymers such as polylactic acid, polypropylene, and polyvinyl alcohol [30]. Macromolecular lignin can have several potential functions in polymeric materials, such as UV degradation or thermo-oxidation stabilizer, lubricant, hydrophobing agent, plasticizer, adsorbent for wastewater purification or starting material for green hydrogels [31, 32].

In the production of carbon fibers from lignin, thermal properties are the critical parameters. In the most common production method, lignin is melt-spun into fiber and then oxidatively thermostabilized and carbonized. This requires that the glass transition temperature $\left(\mathrm{T}_{\mathrm{g}}\right)$ of the materials is low enough for the melt flow technique, but high enough for fast fiber stabilization. Baker et al. determined an optimal $\mathrm{T}_{\mathrm{g}}$ between $130-150{ }^{\circ} \mathrm{C}$ for low molecular weight distribution lignin [33]. A low amount of contaminants is also required in order to produce fibers with good mechanical strength [34]. The precursor for carbon fiber today is polyacrylonitrile (PAN), and lignin has the potential to be used as an alternative to PAN in order to make the process a lot cheaper. Carbon fibers already have a wide range of applications, such as automobile industry, civil engineering, aircrafts and sport goods [35, 36]. Activated carbons are characterized by their surface area and size of pores, and are great adsorbents of organic and inorganic substances. Lignin and lignin-based chars are a good choice for the production of activated carbons after physical or chemical activation [37, 38]. Lignin has also been used for the production of carbon black, which is used as pigment and tire additive [32].

In addition to lignin production in the pulp and paper industry, lignocellulosic biorefinery, mainly for production of biofuel, is expected to generate large quantities of lignin in the future [39]. Valorization of all fractions, and especially lignin, is thus required to achieve a sustainable economy and to reduce our carbon footprint. As there are numerous potential uses for lignin, ranging from chemical platforms to filler materials, it is important to understand the chemical structure and fundamental properties of the lignin in question, and its potential for different applications. The main aim of this work was to characterize two types of lignosulfonate, ammonium and sodium, as well as supercritical water hydrolyzed lignin through elemental analysis, ${ }^{13} \mathrm{C}$ nuclear magnetic resonance $\left({ }^{13} \mathrm{C}\right.$ NMR $)$, Fourier transform infrared (FTIR) spectroscopy, thermogravimetric analysis (TGA), differential scanning calorimetry (DSC) and automated vapor sorption (AVS) analysis. These characterizations should provide further understanding of the mentioned industrial residual lignin types in order to help developing value-added polymers and bioproducts.

\section{Materials and Methods}

\section{Materials}

Ammonium lignosulfonate (A-LS) and sodium lignosulfonate (S-LS) samples were obtained as by-products of commercial biorefinery processes and received from the supplier in dry powder form. Both lignosulfonates were derived mainly from fermented Norway spruce (Picae abies) wood sulphite liquor. The supercritical water hydrolysis (SCWH) lignin was sourced from another industrial partner as a side product of a smaller non-commercial biorefinery batch, and delivered in dry powder form. The composition of the SCWH lignin was $65-85 \%$ lignin, $10-25 \%$ carbohydrates and $<10 \%$ water. The woodmix used for the biorefinery process was mainly Scots pine (Pinus sylvestris) with minor traces of other wood species. Lignin residues were spray dried, but not otherwise modified.

\section{Gel Permeation Chromatography (GPC)}

Weight average molecular weight, $\overline{\mathrm{M}}_{\mathrm{w}}$, and dispersity index (PI) of SCWH lignin was determined by GPC using a Thermo Scientific chromatograph, equipped with an isocratic Dionex UltiMate 3000 pump and a RefractoMax 521 refractive index detector. The separation was carried out at $30{ }^{\circ} \mathrm{C}$ within four Phenogel GPC columns from Phenomenex, with $5 \mu \mathrm{m}$ particle size and 105, 103, 100 and $50 \AA$ porosities, respectively, located in an UltiMate 3000 Thermostated Colum Compartment. Tetrahydrofuran (THF) was used as mobile phase at a flow rate of $1 \mathrm{~mL} \mathrm{~min}^{-1}$. Samples were prepared dissolving them in THF at $1 \mathrm{wt} \%$ and filtering using nylon filters with $2 \mu \mathrm{m}$ pore size. $\overline{\mathrm{M}}_{\mathrm{w}}$, Mn and PI were reported as weight average polystyrene standards.

\section{Elemental Analysis}

The carbon, hydrogen, oxygen, nitrogen and sulfur contents of the lignins were determined by elemental analysis using a EuroVector EA 3000 atomic absorption spectrometer (Pavia, Italy) by heating the samples at $980{ }^{\circ} \mathrm{C}$ with a constant flow of helium. 


\section{Fourier Transform Infrared (FTIR) Spectrometry}

Fourier transform infrared (FTIR) spectrometry of the lignin samples were recorded on a P-Elmer equipment (Seer Green, United Kingdom). Each spectrum was recorded in a frequency range of $400-4000 \mathrm{~cm}^{-1}$ using potassium bromide $(\mathrm{KBr})$ disc with $1 \%(\mathrm{w} / \mathrm{w})$ lignin in powder form. The $\mathrm{KBr}$ was previously oven-dried to reduce interference of water. A background spectrum was collected before measurements.

\section{${ }^{13}$ C Nuclear Magnetic Resonance (NMR) Spectroscopy}

The chemical structure of the lignin samples were analyzed with solid-state ${ }^{13} \mathrm{C}$ NMR using a Bruker Avance III $400 \mathrm{MHz}$ equipment (Billerica, MA, USA). The spectra were recorded using a decoupled sequence at ${ }^{13} \mathrm{C}$ frequency of $100.6338 \mathrm{MHz}$ at $25{ }^{\circ} \mathrm{C}$. Samples were measured at a spinning rate of $10 \mathrm{kHz}$, averaging 4096 scans with a recycling delay of $10 \mathrm{~s}$, a time domain of $2 \mathrm{~K}$, and a spectral width of $30 \mathrm{kHz}$.

\section{Thermogravimetric Analysis (TGA)}

The thermal stability of the lignin samples was analyzed using a NETZSCH STA 409PC instrument (Bayern, Germany), as described previously [40, 41]. Around $5 \mathrm{mg}$ of oven-dried sample $\left(24 \mathrm{~h}\right.$ at $\left.50{ }^{\circ} \mathrm{C}\right)$ were heated from 30 to $800{ }^{\circ} \mathrm{C}$ at a rate of $10^{\circ} \mathrm{C} / \mathrm{min}$ under a flowing nitrogen atmosphere.

\section{Differential Scanning Calorimetry (DSC)}

The glass transition temperatures $\left(\mathrm{T}_{\mathrm{g}}\right)$ of the lignins were determined using a DSC analyzer (Mettler Toledo DSC 3 + equipment, Columbus, OH, USA). Samples were heated from -80 to $250{ }^{\circ} \mathrm{C}$ at a heating rate of $20^{\circ} \mathrm{C} \mathrm{min}^{-1}$ under a nitrogen flow of $10 \mathrm{~mL} / \mathrm{min}$. Approximately $5 \mathrm{mg}$ of oven-dried sample $\left(24 \mathrm{~h}\right.$ at $\left.50{ }^{\circ} \mathrm{C}\right)$ was used for each analysis, as explained previously [40].

\section{Automated Vapor Sorption (AVS) Analysis}

The water vapor sorption behavior of the lignins was determined using an AVS apparatus (Q5000 SA, TA Instruments) as reported previously [41, 42]. Approximately $8 \mathrm{mg}$ of each lignin sample was exposed to relative humidity $(\mathrm{RH})$ increased from 0 to $90 \%$ in step sequences of $10 \%$ and of 5\% from 90 to $95 \% \mathrm{RH}$. The instrument maintained a constant target RH until the mass change in the sample $(\mathrm{dm} /$ dt) was less than $0.01 \%$ per minute over a 10 min period. The target $\mathrm{RH}$, actual $\mathrm{RH}$, sample mass and running time were recorded every $30 \mathrm{~s}$ during the adsorption run. The equilibrium moisture content (EMC) of the each lignin was calculated based on their equilibrium weight at each given RH step throughout the adsorption run.

\section{Figures}

All figures were done using Microsoft Excel and Microsoft Word.

\section{Results and Discussion}

\section{Gel Permeation Chromatography (GPC) and Elemental Analysis.}

The SCWH lignin had number average molecular weight, $\mathrm{Mn}$, of $577 \mathrm{Da}$, and weight average molecular weight, $\overline{\mathrm{M}}_{\mathrm{w}}$, of $1065 \mathrm{Da}$, and thus polydispersity $\left(\mathrm{Mn} / \overline{\mathrm{M}}_{\mathrm{w}}\right)$ of 1.84 , referred to calibration with polystyrene standards. The low average molecular weight indicates severe fragmentation of the lignin polymers. Molecular weight of the tested SCWH lignin was even lower than what has previously been reported for SCWH lignins ( $\overline{\mathrm{M}}_{\mathrm{w}} 3369 \mathrm{Da}$ and $2003 \mathrm{Da}$, and Mn $1216 \mathrm{Da}$ and $1009 \mathrm{Da}$ ) [17]. Direct comparison to lignosulfonates could not be performed, as the THF-based GPC method is not suitable for the commercial highly polar lignosulfonates, which are not soluble in organic solvents such as THF. The supplier reported average molecular weight ranges of $37.000-53.000 \mathrm{~g} / \mathrm{mol}$ for A-LS and $35.000-51.000 \mathrm{~g} / \mathrm{mol}$ for S-LS measured using GPC. For dispersant applications, high molecular weight is important factor as it results in smaller particle size of the liquid being dispersed [43]. The

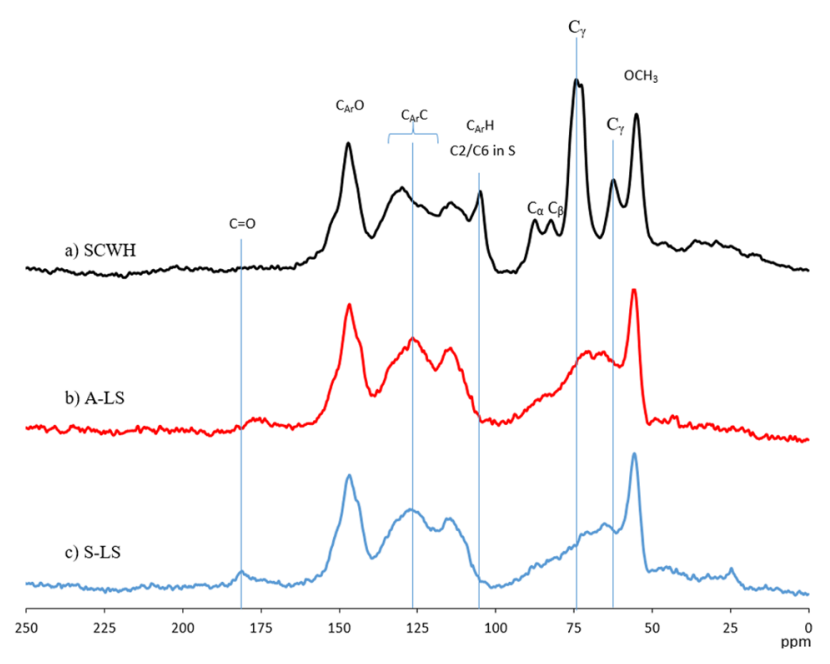

Fig. 1 Solid state ${ }^{13} \mathrm{C}$ NMR spectra of a) supercritical water hydrolysis lignin (SCWH), b) ammonium lignosulfonate (A-LS) and c) sodium lignosulfonate (S-LS). Signals with most significant differences are marked with vertical lines 
molecular weights of lignosulfonates were greater than that of SCWH, even though the values are not directly comparable due to different determination methods. The results of elemental composition of SCWH, A-LS and S-LS lignins are present in Table 1.

The results indicated a considerable amount of carbon content in SCWH lignin (59.0\%). The carbon content of A-LS and S-LS were $43.7 \%$ and $41.1 \%$, respectively. This is in accordance to previous studies [39, 44], which reported a low carbon content for lignosulfonate lignins. The oxygen content of the lignins reduced in the order from $\mathrm{SCWH}>\mathrm{S}$ LS $>$ A-LS. S-LS illustrated the highest $\mathrm{O} / \mathrm{C}$ ratio in comparison with the other lignin types, which makes it least suitable for energy-oriented utilization. A small amount of nitrogen was found in A-LS lignin (4.0\%), which might be due to the presence of ammonium in the extraction method. The nitrogen content of the other two samples can vary due to differences in the raw material source or protein presence [39]. The amount of other compounds calculated by subtracting from $100 \%$ include mainly inorganic materials. The low amount of impurities in SCWH (5.4\%) provides good possibilities for value-added applications for this lignin type while the high amount in lignosulfonates (20.4 for A-LS and $21.0 \%$ S-LS) is a known limiting factor [2]. S-LS had slightly higher sulfur content (6.0\%) than A-LS (5.5\%). Lignosulfonates with high sulfur content have been found to be better dispersants for cement and coal-water slurry [45].

\section{Chemical Structure}

The chemical structures of SCWH, A-LS and S-LS were analyzed by means of solid state ${ }^{13} \mathrm{C}$ NMR (Fig. 1). SCWH lignin showed no significant signals in the area 200-160 ppm, indicating a low amount of $\mathrm{C}=\mathrm{O}$ structures [46]. The presence of respective peaks at $177.5 \mathrm{ppm}$ and $181.0 \mathrm{ppm}$ in A-LS and S-LS might be attributed to the $\mathrm{C}=\mathrm{O}$ bonds in $\mathrm{Ar}-\mathrm{CHO}$ or $\mathrm{R}-\mathrm{O}-\mathrm{CO}-\mathrm{CH}_{3}$. These signals can also be traced to the dehydration reaction of lignin side chains in acidic conditions (Hibbert's ketone) [47]. A shoulder to the $\mathrm{C}_{\mathrm{Ar}} \mathrm{O}$ peak could be detected at $144.0 \mathrm{ppm}$ for A-LS and at $144.2 \mathrm{ppm}$ for S-LS that could be connected to sulfonate $\left(\mathrm{C}-\mathrm{S}=\mathrm{O}_{3}\right)$ structures.

In the $\mathrm{C}_{\mathrm{Ar}}-\mathrm{C}$ region, the strongest signal for $\mathrm{SCWH}$ lignin was at $129.9 \mathrm{ppm}$, while it was at a lower value for

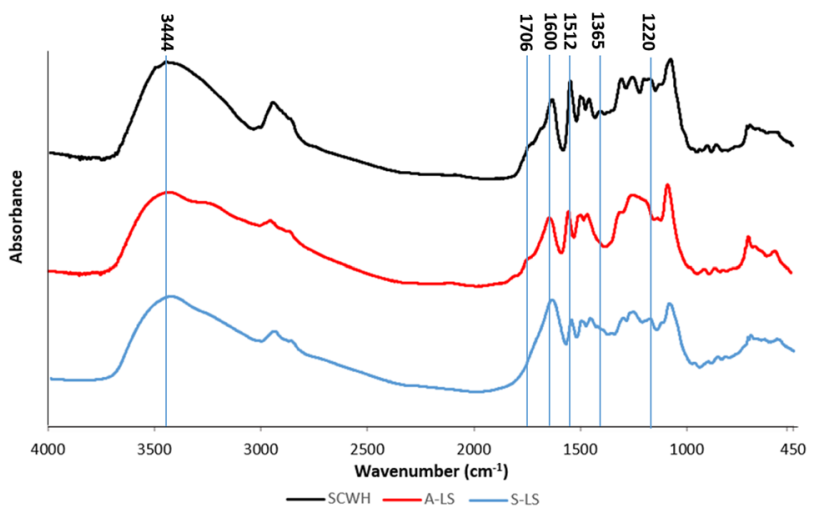

Fig. 2 FTIR spectra of supercritical water hydrolysis lignin (SCWH), ammonium lignosulfonate (A-LS) and sodium lignosulfonate (S-LS). Signals with most significant differences are marked with vertical lines

the lignosulfonates (at $129.0 \mathrm{ppm}$ for A-LS and $127.4 \mathrm{ppm}$ for A-LS). The lower value can be due to interferences from doublebond structures such as $\mathrm{C}_{\beta}$ in $\mathrm{Ar}-\mathrm{CH}=\mathrm{CH}-\mathrm{CHO}$ or $\mathrm{Ar}-\mathrm{CH}=\mathrm{CH}-\mathrm{CH}_{2} \mathrm{OH}[46,48]$. SCWH lignin showed an intense signal at $104.9 \mathrm{ppm}$ that was missing in A-LS and S-LS. This can refer to $\mathrm{C}_{2} / \mathrm{C}_{6}$ carbons of syringyl-type (S-type) lignins, indicating that unlike the SCWH lignin neither lignosulfonate had S-type lignin [49]. The observation of two peaks at 82.6 and $87.5 \mathrm{ppm}$ in SCWH can be attributed to the $\mathrm{C}_{\beta}$ in guaiacyl (G-unit) $\beta-O-4$ units and to $\mathrm{C}_{\alpha}$ in G-unit $\beta-5$ units, respectively [46]. The distinct $C_{\gamma}$ signals at 74.2 and $72.6 \mathrm{ppm}$ in SCWH lignin can refer to either $\beta-\beta$ or $\beta$-aryl ester structures [49]. The chemical shift at $62.3 \mathrm{ppm}$ in SCWH can correspond to the $\mathrm{C}_{\gamma}$ in G-unit $\beta-5$ or $\beta-1$ units [46]. The A-LS lignin exhibited two signals at $70.2 \mathrm{ppm}$ and $65.4 \mathrm{ppm}$. Identical peaks were observed in S-LS lignin but the peak intensity was higher at $65.1 \mathrm{ppm}$ than the one at $70.7 \mathrm{ppm}$. These can originate from the $\mathrm{C}_{\gamma}$ in $\beta-O-4$ structure with interference from $\alpha-\mathrm{C}=\mathrm{O}$ and from $\alpha$ - carbon in G type $\beta-O-4$ linkage, respectively [48]. Spectrum of S-LS also showed a signal at $24.6 \mathrm{ppm}$ that can be connected to the $\mathrm{CH}_{3}$ or $\mathrm{CH}_{2}$ group in saturated aliphatic chains [48].

The $\beta-O-4, \beta-5, \beta-1$, and $\beta-\beta$ type of linkages were more obvious in the SCWH lignin than the lignosulfonates, while the lignosulfonates exhibited a considerable amount of doublebonds in the aliphatic chain. The presence of $\mathrm{C}=\mathrm{O}$ bonds
Table 1 Elemental analysis of supercritical water hydrolysis lignin $(\mathrm{SCWH})$, ammonium lignosulfonate (A-LS) and sodium lignosulfonate (S-LS)

\begin{tabular}{llllllll}
\hline Lignin type & $\% \mathrm{C}$ & $\% \mathrm{H}$ & $\% \mathrm{~N}$ & $\% \mathrm{O}$ & $\% \mathrm{~S}$ & $\%$ other** & O/C ratio \\
\hline SCWH & 59.0 & 6.3 & $0 *$ & 29.3 & $0 *$ & 5.4 & 0.50 \\
A-LS & 43.7 & 5.5 & 4.0 & 20.9 & 5.5 & 20.4 & 0.48 \\
S-LS & 41.1 & 4.5 & 0.3 & 27.1 & 6.0 & 21.0 & 0.66 \\
\hline
\end{tabular}

*Quantity too low to be determined

$* * \%$ other was calculated by subtracting from $100 \%$ 
was confirmed in the A-LS and S-LS lignin samples, but not in the SCWH lignin.

FTIR absorption band assignment and spectra of SCWH, A-LS and S-LS lignin samples are shown in Table 2 and Fig. 2. Hardwood lignins can have different amounts of G-units (guaiacyl) and S-units (syringyl), while softwood lignin mainly has G-units. The typical G-bands are at 1270 , 1125,855 , and $810 \mathrm{~cm}^{-1}$ and the typical S-bands are at 1326,1115 , and $825 \mathrm{~cm}^{-1}$. There were no peaks observed at $1115 \mathrm{~cm}^{-1}$ (aromatic $\mathrm{C}-\mathrm{H}$ in-plane deformation of S-ring), at $825 \mathrm{~cm}^{-1}$ (C-H out-of-plane deformation in $\mathrm{C}_{2}$ and $\mathrm{C}_{6}$ of S-unit) or at $843 \mathrm{~cm}^{-1}$ (C-H out-of-plane deformation in $\mathrm{C}_{2}$ and $\mathrm{C}_{6}$ of $\mathrm{S}$ unit) in A-LS and S-LS lignin samples [50, 51], confirming a lack of S-type lignin in the lignosulfonates. In SCWH lignin, the only S-band vibration observed was at $1326 \mathrm{~cm}^{-1}$, indicating a small amount of S-type lignin. Small amounts of syringylpropane units in softwood lignins have been previously reported [52]. Thetypical G-ring vibrations were strong in all lignins, especially the vibration at $1270 \mathrm{~cm}^{-1}$ (G-ring breathing) [53].
The absorption bands between 3410 and $3460 \mathrm{~cm}^{-1}$ were attributed to the aromatic and aliphatic $\mathrm{OH}$ groups. A-LS lignin showed slightly lower stretching vibration of the $\mathrm{OH}$ group than the other lignin types, which might be due to ammonium group. The peaks at 2938 and $2842 \mathrm{~cm}^{-1}$ were due to the $\mathrm{CH}$ stretching of both the aromatic methoxyl groups as well as the methyl and methylene in the side chains. The vibration at 1600,1515 , and $1425 \mathrm{~cm}^{-1}$ corresponded to the aromatic ring vibration of the phenyl propane 9C skeleton [50].

The SCWH lignin and the A-LS lignin showed peaks at $1705-1720 \mathrm{~cm}^{-1}$, which is related to the unconjugated carbonyl stretching vibration [56]. These peaks cannot be identified in S-LS lignin due to the strong aromatic skeletal vibrations in connection to the $\mathrm{C}=\mathrm{O}$ signal at $1600 \mathrm{~cm}^{-1}$. The ratio of absorbance of the $\mathrm{C}=\mathrm{O}$ signal at $1600 \mathrm{~cm}^{-1}$ $\left(\mathrm{A}_{1600}\right)$ to the aromatic "standard" ring vibration of the phenyl propane 9C skeleton at $1515 \mathrm{~cm}^{-1}\left(\mathrm{~A}_{1515}\right)$ [53] was 1.18 for S-LS, but only 0.63 for A-LS and 0.64 for SCWH, which indicates a much higher amount of $\mathrm{C}=\mathrm{O}$ groups in the $\mathrm{S}-\mathrm{LS}$.

Table 2 FTIR absorption band assignments of supercritical water hydrolysis lignin (SCWH), ammonium lignosulfonate (A-LS) and sodium lignosulfonate (S-LS) [50, 54, 55]

\begin{tabular}{|c|c|c|c|c|}
\hline Band $\left(\mathrm{cm}^{-1}\right)$ & Assignments & $\mathrm{SCWH}$ & A-LS & S-LS \\
\hline \multirow[t]{2}{*}{$3412-3460$} & $\mathrm{O}-\mathrm{H}$ stretching (phenolic and aliphatic $\mathrm{OH}$ ) & 3445 & 3409 & 3433 \\
\hline & $\mathrm{O}-\mathrm{H}$ stretching (phenolic and aliphatic $\mathrm{OH}$ ) & & 3214 & \\
\hline $2960-2925$ & $\mathrm{C}-\mathrm{H}$ stretching $\left(\mathrm{CH}_{3}\right.$ and $\left.\mathrm{CH}_{2}\right)$ & 2932 & 2939 & 2937 \\
\hline $2850-2840$ & $\mathrm{C}-\mathrm{H}$ stretching $\left(\mathrm{OCH}_{3}\right)$ & 2839 & 2836 & 2842 \\
\hline 1771 & Aromatic acetoxy group & - & 1772 & - \\
\hline $1705-1720$ & $\mathrm{C}=\mathrm{O}$ stretching (unconjugated carbonyl) & 1707 & 1703 & - \\
\hline 1650 & $\mathrm{C}=\mathrm{O}$ stretching (conjugated) & 1656 & - & - \\
\hline$\sim 1600$ & $\mathrm{C}=\mathrm{C}$ stretching (aromatic skeleton) with $\mathrm{C}=\mathrm{O}$ stretching & 1600 & 1603 & 1604 \\
\hline$\sim 1513$ & $\mathrm{C}=\mathrm{C}$ stretching (aromatic skeleton) & 1513 & 1512 & 1512 \\
\hline 1460 & $\mathrm{C}-\mathrm{H}$ deformation (asymmetric in $\mathrm{CH}_{3}$ and $\mathrm{CH}_{2}$ ) combined with $\mathrm{C}-\mathrm{H}$ in-plane deformation & 1464 & 1463 & 1464 \\
\hline$\sim 1425$ & $\mathrm{C}=\mathrm{C}$ stretching (aromatic skeleton) with $\mathrm{C}-\mathrm{H}$ in-plane deformation (aromatic skeleton) & 1424 & 1429 & 1421 \\
\hline $1365-1370$ & $\mathrm{H}-\mathrm{O}$ in-plane deformation (phenolic $\mathrm{OH}$ ) and $\mathrm{C}-\mathrm{H}$ in methyl groups & 1367 & - & - \\
\hline $1325-1330$ & S-ring breathing with $\mathrm{C}=\mathrm{O}$ stretching or G-ring substituted in $\mathrm{C}_{5}$ & 1332 & - & - \\
\hline $1266-1270$ & G-ring breathing with $\mathrm{C}-\mathrm{O}$ stretching & 1269 & 1266 & 1264 \\
\hline $1215-1220$ & $\mathrm{C}-\mathrm{C}$ with $\mathrm{C}-\mathrm{O}$ and $\mathrm{C}=\mathrm{O}$ stretching & 1220 & 1206 & 1210 \\
\hline $1195-1168$ & $\mathrm{~S}=\mathrm{O}$ stretching (symmetric) & - & 1173 & 1180 \\
\hline 1166 & $\mathrm{C}=\mathrm{O}$ (conjugated ester groups) & 1159 & 1162 & - \\
\hline 1140 & Aromatic $\mathrm{C}-\mathrm{H}$ in-plane deformation (G-ring) & - & - & 1141 \\
\hline 1115 & Aromatic $\mathrm{C}-\mathrm{H}$ in-plane deformation (S-ring) & 1122 & - & - \\
\hline 1086 & $\mathrm{C}-\mathrm{O}$ deformation (secondary alcohols and aliphatic esters) & 1077 & 1087 & 1088 \\
\hline $1030-1035$ & $\begin{array}{l}\text { Aromatic } \mathrm{C}-\mathrm{H} \text { in-plane deformation with } \mathrm{C}-\mathrm{O} \text { deformation (primary alcohol and ether) and } \\
\mathrm{C}=\mathrm{O} \text { stretching (unconjugated) }\end{array}$ & 1030 & 1036 & 1043 \\
\hline $915-925$ & $\mathrm{C}-\mathrm{H}$ out-of-plane bending (aromatic ring) & 930 & 927 & 929 \\
\hline $853-858$ & $\mathrm{C}-\mathrm{H}$ out-of-plane bending $\left(\mathrm{C}_{2}, \mathrm{C}_{5}\right.$, and $\mathrm{C}_{6}$ of G-ring $)$ & 857 & 866 & 863 \\
\hline $817-832$ & $\mathrm{C}-\mathrm{H}$ out-of-plane bending $\left(\mathrm{C}_{2}, \mathrm{C}_{5}\right.$, and $\mathrm{C}_{6}$ of G-ring $)$ & 815 & 814 & 815 \\
\hline 620 & Sulphonic groups $(\mathrm{S}-\mathrm{O})$ & - & 616 & - \\
\hline
\end{tabular}


The $1515 \mathrm{~cm}^{-1}$ band was used for determination as it has the least interference from overlapping effects [57].

The cleaving of $\alpha-O-4$ and $\beta-O-4$ linkages leaves many non-etherified phenolic $\mathrm{OH}$ groups in lignin, which can be visible in the $1365 \mathrm{~cm}^{-1}$ band. The SCWH lignin showed a strong signal at $1367 \mathrm{~cm}^{-1}$ and $1220 \mathrm{~cm}^{-1}$ which can be associated with the $\mathrm{C}-\mathrm{C}$ with the $\mathrm{C}-\mathrm{O}$ and $\mathrm{C}=\mathrm{O}$ stretching [50]. Comparing the absorbance of the $\mathrm{OH}$ signals around $3430 \mathrm{~cm}^{-1}$ and the phenolic $\mathrm{OH}$ signals at 1365 and $1328 \mathrm{~cm}^{-1}$ gives information about the relative amounts of aliphatic and phenolic $\mathrm{OH}$ groups [53]. The FTIR spectra indicated more phenolic $\mathrm{OH}$ groups in the SCWH lignin, and more aliphatic $\mathrm{OH}$ groups in the A-LS and S-LS lignin samples.

\section{Thermogravimetric Analysis (TGA)}

The thermal decomposition of lignin samples was evaluated using thermogravimetric (TGA) and derivative thermogravimetric (DTG) analyses. Figure 3a illustrates the weight losses of the lignin samples with increasing temperature, and Fig. $3 \mathrm{~b}$ shows the first derivatives of the TG curves that provide information on the rate of mass change with the decomposition temperatures of samples.

Initial weight losses were observed at temperatures below $160{ }^{\circ} \mathrm{C}$, which can be ascribed to the removal of physically bound moisture from the lignin samples [58]. SCWH lignin showed highest degradation temperature $\left(\mathrm{T}_{\text {onset }}\right)$ as compared with the A-LS and S-LS lignins. The respective $T_{\text {onset }}$ of
SCWH, A-LS and S-LS were 314, 231 and $217^{\circ} \mathrm{C}$ (Table 3). S-LS lignin showed lower mass change and higher residual mass than A-LS and SCWH. This can be attributed to the higher decomposition degree of S-LS caused by the more severe pulping process $[59,60]$, and partially to the existence of inorganic impurities [39], as indicated in the results of the elemental analysis. The DTG curves demonstrate the maximum temperatures at which weight loss occurred in the lignin polymers. As indicated in Table 3, the first maximum degradation temperatures $\left(\mathrm{T}_{\max 1}\right)$ in A-LS and S-LS were at 266 and $257^{\circ} \mathrm{C}$, respectively. These could be associated with degradation of impurities and hemicelluloses [61]. SCWH showed $\mathrm{T}_{\max 1}$ at $369{ }^{\circ} \mathrm{C}$ and second maximum degradation temperature $\left(\mathrm{T}_{\max 2}\right)$ at 395 , while the $\mathrm{T}_{\max 2}$ in A-LS was at $376^{\circ} \mathrm{C}$ and in S-LS at $322^{\circ} \mathrm{C}$. This $350-400{ }^{\circ} \mathrm{C}$ range can be related to the fragmentation of inter-unit linkages and releasing of monomeric phenols [62]. Unlike the other lignin samples, S-LS showed a third maximum degradation temperature $\left(\mathrm{T}_{\max 3}\right)$ at $760{ }^{\circ} \mathrm{C}$. Loss of mass above $500{ }^{\circ} \mathrm{C}$ could be caused by the degradation of aromatic rings [62] or by the release of $\mathrm{CO}$ from degenerating $\mathrm{C}-\mathrm{O}-\mathrm{C}$ and $\mathrm{C}=\mathrm{O}$ bonds [39]. High amounts of $\mathrm{C}=\mathrm{O}$ groups in $\mathrm{S}-\mathrm{LS}$ is supported by the findings from elemental analysis, FTIR, and ${ }^{13} \mathrm{C}$ NMR.

\section{Differential Scanning Calorimetry (DSC)}

Figure 4 shows the glass transition temperatures $\left(\mathrm{T}_{\mathrm{g}}\right)$ of the lignin samples after removing thermal history. The $\mathrm{T}_{\mathrm{g}}$ of SCWH and S-LS were found to be 150.5 and $152.1^{\circ} \mathrm{C}$,
Fig. 3 a Thermograms (TG) and $\mathbf{b}$ derivate of thermograms (DTG) of supercritical water hydrolysis lignin (SCWH), ammonium lignosulfonate (A-LS) and sodium lignosulfonate (S-LS)
Table 3 Degradation temperatures for supercritical water hydrolysis lignin (SCWH), ammonium lignosulfonate (A-LS) and sodium lignosulfonate (S-LS) (a)

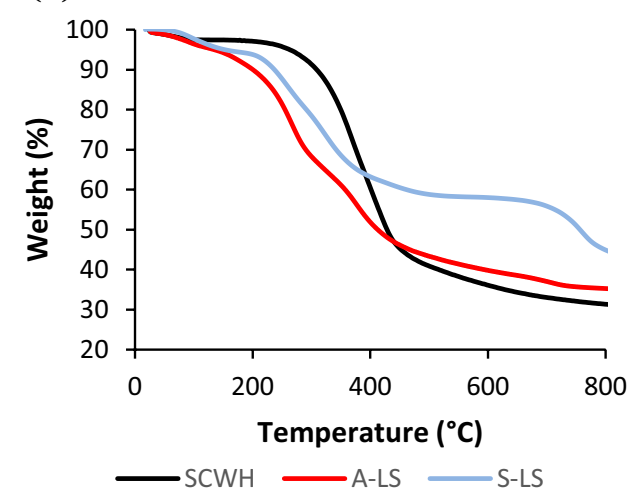

(b)

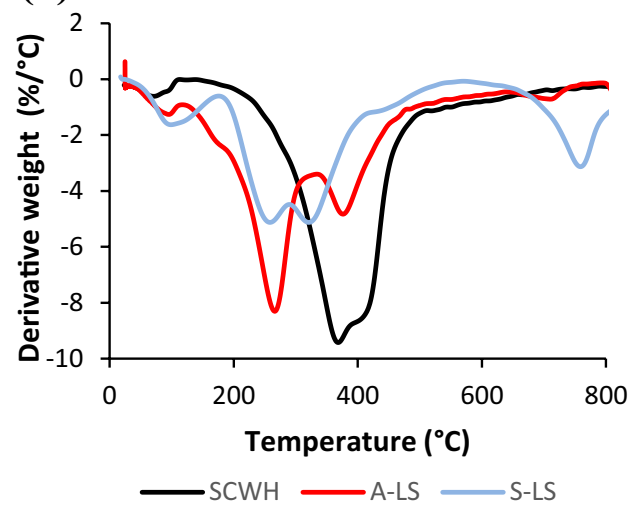

\begin{tabular}{|c|c|c|c|c|c|c|}
\hline \multirow[t]{2}{*}{ Type of lignin } & \multirow[t]{2}{*}{ Onset $\left({ }^{\circ} \mathrm{C}\right)$} & \multirow[t]{2}{*}{$\begin{array}{l}\text { Mass change } \\
200-600{ }^{\circ} \mathrm{C}(\%)\end{array}$} & \multicolumn{3}{|c|}{$\begin{array}{l}\text { Major degradation temperatures } \\
\left({ }^{\circ} \mathrm{C}\right)\end{array}$} & \multirow{2}{*}{$\begin{array}{l}\text { Residual } \\
\text { mass } \\
(\%)\end{array}$} \\
\hline & & & $\mathrm{T}_{\max 1}$ & $\mathrm{~T}_{\max 2}$ & $\mathrm{~T}_{\max 3}$ & \\
\hline SCWH & 314 & 60.9 & 369 & 395 & - & 31.2 \\
\hline A-LS & 231 & 50.4 & 266 & 376 & - & 35.2 \\
\hline S-LS & 217 & 35.8 & 257 & 322 & 760 & 44.3 \\
\hline
\end{tabular}




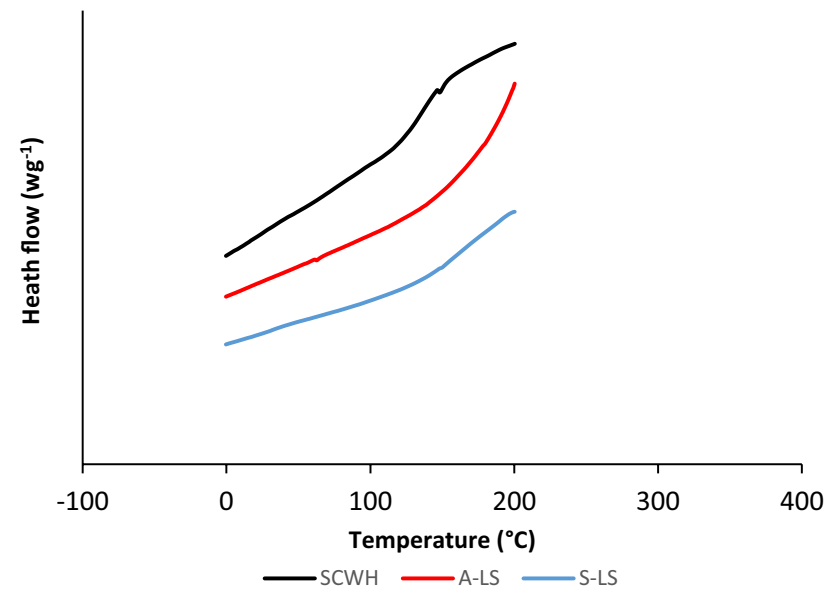

Fig. 4 DSC curves of supercritical water hydrolysis lignin (SCWH), ammonium lignosulfonate (A-LS) and sodium lignosulfonate (S-LS) with labeled $\mathrm{T}_{\mathrm{g}}$ 's

respectively. In the literature, $\mathrm{T}_{\mathrm{g}}$ values of different lignin types varies between 90 and $180^{\circ} \mathrm{C}$ [62], the determined $\mathrm{T}_{\mathrm{g}}$ values for SCWH and S-LS lignins were therefore relatively high. High $\mathrm{T}_{\mathrm{g}}$ values can be explained by higher molecular weight and stiffer chains [63]. A-LS lignin did not show a $T_{g}$, which might be due to the hydrophilicity of this lignin type, as water is a disturbing factor in $\mathrm{T}_{\mathrm{g}}$ determination [53]. $\mathrm{T}_{\mathrm{g}}$ is important parameter in processes using extrusion, such as carbon fiber production [33]. Although DSC is an accepted method for determining the $T_{g}$ of lignin [64], difficulties with the method have been discussed previously [62].

\section{Automated Vapor Sorption (AVS) Analysis}

Lignin is a relatively hydrophobic polymer due to the presence of phenyl groups on its basic chain unit. Water molecules are capable of breaking the hydrogen bonds between lignin molecules and form separate hydrogen bonds with available hydroxyl groups (bound water). When hydroxyl sites are saturated, additional water molecules (free water) aggregate through intermolecular hydrogen bonding [65] Lignin moisture sorption isotherms have been determined previously by using gravitational methods and dynamic vapor sorption [66, 67].

The water vapor sorption of the three lignin types is shown in Fig. 5a. Lignosulfonate lignins exhibited higher equilibrium moisture content (EMC) as compared to the SCWH lignin at the whole RH range, and especially at the RHs above $60 \%$. SCWH showed an EMC of $6.5 \%$ at 95\% RH, while the respective EMC values of A-LS and S-LS were $46.7 \%$ and $55.9 \%$. The moisture increment of the SCWH lignin was low and varied little over the entire RH range (Fig. 5b). In the case of lignosulfonates, moisture increment slightly decreased from 0 to $40 \% \mathrm{RH}$ in A-LS lignin, then gradually increased from 40 to $60 \%$, and then strongly increased above $60 \%$. S-LS lignin, however, showed almost constant increment up to $30 \% \mathrm{RH}$, then slight increment from 30 to $40 \% \mathrm{RH}$ and sharp increment from 40 to $90 \%$ RH. Greater moisture increment was observed for all samples in the range of $80-90 \% \mathrm{RH}$ than in the RH range of $90-95 \%$. The latter can be due to a reduction in a number of accessible $\mathrm{OH}$ groups. The different EMC behavior of the lignins might be attributed to the presence of less phenolic hydroxyl groups and more available $\mathrm{OH}$ groups, and/or to the highly amorphous structure of lignosulfonate lignins. This leads to increased elastic swelling of the lignin polymer upon higher RHs, and subsequently to more accommodation possibility for water molecules in lignosulfonates [68]. Larger amounts of carbohydrates in lignosulfonates than in SCWH lignin, as indicated by the elemental analysis and TGA, may also be an additional reason.

The relative stable sorption behavior of SCWH lignin implies a less moisture dependent hydromechanical response [69], which makes this material promising as reinforcement in polymer composites [70]. The adsorption characteristics
Fig. 5 a Equilibrium moisture content (EMC) in adsorption and $\mathbf{b}$ moisture increment of supercritical water hydrolysis lignin (SCWH), ammonium lignosulfonate (A-LS) and sodium lignosulfonate (S-LS) (a)

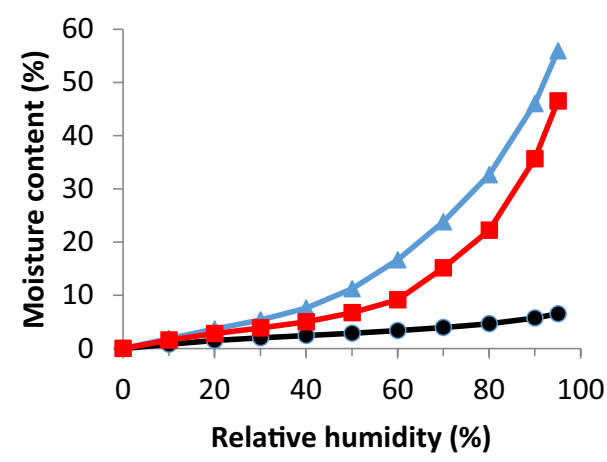

$\longrightarrow$ SCWH $\rightarrow$ S-LS $\rightarrow$ A-LS (b)
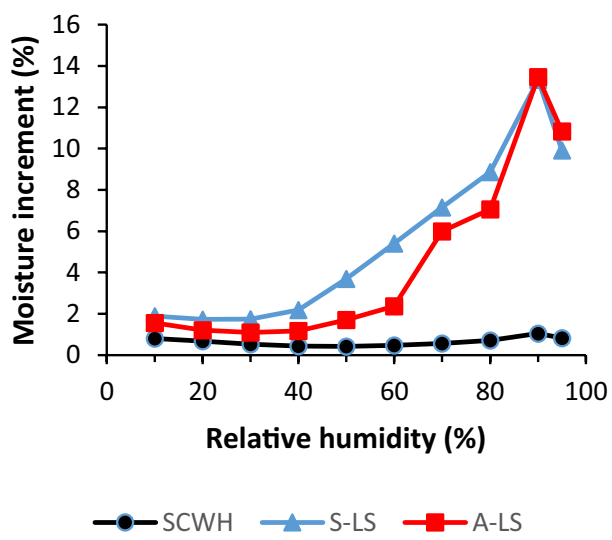
have a close relationship with the solution behaviors of lignosulfonates [71]. Thus, the favorable water absorptivity of A-LS and S-LS should be beneficial for their solution behavior and applied performance at solid-liquid interfaces in systems involving coal/ water, air/liquid interfaces and metallic oxides [45, 72].

\section{Conclusions}

As the supply of residual lignin from pulping industries and biorefineries increases, the information presented in this study on the properties of different lignin types will contribute to the growing effort to recover these renewable resources for higher-value utilization, as opposed to simply burning them for internal energy generation. The overall results showed that SCWH lignin differed greatly from the lignosulfonates A-LS and S-LS in chemical structure, thermal properties and water sorption behavior. It was found to have more $\beta$ - $\mathrm{R}$ linkages than the lignosulfonates, where $\mathrm{R}$ can be $\beta$, aryl ester (e.g. - $O-4$ ), 5 or 1 carbon. High amounts of $\beta-O-4$ linkages as well as the low molecular weight make it interesting to consider conversion of SCWH lignin into aromatic compounds. For lignosulfonates, little effect is expected from the milder depolymerization methods. Full depolymerization into platform chemicals might be possible for the lignosulfonates, but would require removal of the impurities detected in relative high amounts by elemental analysis and TGA.

Based on ${ }^{13} \mathrm{C}$ NMR and FTIR, all lignins had mainly G-units, and only SCWH lignin showed indications of containing some S-units. Relatively high reactivity can thus be expected, as G-units have more free reactive sites than S-units. This is important in adhesive applications, such as phenol replacement in phenol formaldehyde resins [27, 73].

According to the FTIR results, the total hydroxyl content was similar for all lignins, whereas SCWH lignin had higher phenolic hydroxyl and lignosulfonates higher aliphatic hydroxyl content. Aliphatic hydroxyl groups are beneficial for modifications such as acetylation and alkylation of lignins. A high total content of hydroxyl groups is important when lignin is used in adhesives or as reinforcement in polymer blends. For polymer applications, the lignosulfonates would need to be purified due to their high ash content [59]. However, the higher $\mathrm{C}=\mathrm{O}$ content of S-LS might provide interesting application opportunities.

Both SCWH lignin and S-LS (after purification) may have potential to be used as raw materials for carbon fibers, having $\mathrm{Tg}$ of 150.5 and $152.1{ }^{\circ} \mathrm{C}$, respectively. Alternative methods, such as dry spinning, might be required due to the relatively high $\mathrm{T}_{\mathrm{g}}$ [74]. The more economical option of the two would be SCWH, as it would not require as intensive purification as the S-LS.
Water vapor adsorption analysis showed little EMC change within the RH range for the SCWH lignin. It can thus find uses as a hydrophobic reinforcement material in polymer composites with improved hydromechanical properties [70]. On the other hand, the high adsorptivity of lignosulfonates should favor the classic uses as anionic surfactants in various application areas, such as concrete water reducers and dispersants [71].

Acknowledgements Open access funding provided by Linnaeus University. Venla Hemmilä and Stergios Adamopoulos would like to thank the Knowledge Foundation for the financial support (project titled "New environment-friendly board materials", 2015-2019). Arantxa Eceiza thanks the Basque Government (IT776-16) and SgiKer General Services of the University of the Basque Country

\section{Compliance with Ethical Standards}

Conflicts of interest The authors have no conflicts of interest to disclose.

Open Access This article is distributed under the terms of the Creative Commons Attribution 4.0 International License (http://creativeco mmons.org/licenses/by/4.0/), which permits unrestricted use, distribution, and reproduction in any medium, provided you give appropriate credit to the original author(s) and the source, provide a link to the Creative Commons license, and indicate if changes were made.

\section{References}

1. Ragauskas, A., et al.: Lignin valorization: improving lignin processing in the biorefinery. Science 344(6185), 1246843 (2014)

2. Holladay, J., et al.,: Top value added chemicals from bio-mass: results of screening potential candidates from biorefinery lignin, vol. 2 (2007)

3. Azadi, P., et al.: Liquid fuels, hydrogen and chemicals from lignin: a critical review. Renew. Sustain. Energy Rev. 21, 506523 (2013)

4. Calvo-Flores, F.G.: Lignin and lignans as renewable raw materials: chemistry, technology and applications. In: Dobado Jiménez, J.A., Garcia, J.I., Martín-Martínez, F.J. (eds.). Wiley, Chichester (2015)

5. Chakar, F.S., Ragauskas, A.J.: Review of current and future softwood kraft lignin process chemistry. Ind. Crops Prod. 20(2), 131-141 (2004)

6. Aro, T., Fatehi, P.: Production and application of lignosulfonates and sulfonated lignin. Chemsuschem 10, 1861-1877 (2017)

7. Chen, J., et al.: Production of flocculants, adsorbents, and dispersants from lignin. Molecules 23(4), 868 (2018)

8. Zhou, M., et al.: Properties of different molecular weight sodium lignosulfonate fractions as dispersant of coal-water slurry. J. Dispers. Sci. Technol. 27(6), 851-856 (2006)

9. Abdulkhani, A., et al.: Concurrent production of sodium lignosulfonate and ethanol from bagasse spent liquor. J. Environ. Manag. 231, 819-824 (2019)

10. Kim, S., et al.: Characterisation of enzymatically oxidised lignosulfonates and their application on lignocellulosic fabrics. Polym. Int. 58(8), 863-868 (2009) 
11. Lebo, S.E., et al.: Recent advances in the characterization of lignosulfonates. In: Characterization of Lignocellulosic Material, pp. 189-205. Wiley, Hoboken (2009)

12. Guizani, C., Lachenal, D.: Controlling the molecular weight of lignosulfonates by an alkaline oxidative treatment at moderate temperatures and atmospheric pressure: a size-exclusion and reverse-phase chromatography study. Int. J. Mol. Sci. 18(12), 2520 (2017)

13. Kruse, A., Dahmen, N.: Water-a magic solvent for biomass conversion. J. Supercrit. Fluids 96, 36-45 (2015)

14. Cantero, D.A., et al.: Reaction engineering for process intensification of supercritical water biomass refining. J. Supercrit. Fluids 96, 21-35 (2015)

15. Fang, Z., et al.: Reaction chemistry and phase behavior of lignin in high-temperature and supercritical water. Biores. Technol. 99(9), 3424-3430 (2008)

16. Wahyudiono, T., et al.: Decomposition of a lignin model compound under hydrothermal conditions. Chem. Eng. Technol. 30(8), 1113-1122 (2007)

17. Moon, S.-J., et al.: Characterization of lignin-rich residues remaining after continuous super-critical water hydrolysis of poplar wood (Populus albaglandulosa) for conversion to fermentable sugars. Biores. Technol. 102(10), 5912-5916 (2011)

18. Cocero, M.J., et al.: Understanding biomass fractionation in subcritical \& supercritical water. J. Supercrit. Fluids 133, 550-565 (2018)

19. Costello, H.: Lignin products global market size, sales data 20172022 \& applications in animal feed industry (Market Analysis No. 188450). Orbis Research, Dallas (2017)

20. Farag, S., et al.: Lumped approach in kinetic modeling of microwave pyrolysis of Kraft lignin. Energy Fuels 28(2), 1406-14171406-1417 (2014)

21. Jiang, W., et al.: Supercritical water-induced lignin decomposition reactions: a structural and quantitative study. BioResources 11(3), 5660-5675 (2016)

22. Hodásová, L., et al.: Lignin, potential products and their market value. Wood Res. 60, 973-986 (2015)

23. Huang, X., et al.: Catalytic depolymerization of lignin and woody biomass in supercritical ethanol: influence of reaction temperature and feedstock. ASC Sustain. Chem. Eng. 5(11), 10864-10874 (2017)

24. Shu, R., et al.: Investigation on the structural effect of lignin during the hydrogenolysis process. Biores. Technol. 200, 14-22 (2016)

25. Rahimi, A., et al.: Formic-acid-induced depolymerization of oxidized lignin to aromatics. Nature 515, 249 (2014)

26. Rinaldi, R., et al.: Paving the way for lignin valorisation: recent advances in bioengineering, biorefining and catalysis. Angew Chem. Int. Ed. 55(29), 8164-8215 (2016)

27. Hemmilä, V., et al.: Development of sustainable bio-adhesives for engineered wood panels: a review. RSC Adv. 7(61), 38604-38630 (2017)

28. El Mansouri, N.E., Salvado, J.: Structural characterization of technical lignins for the production of adhesives: application to lignosulfonate, kraft, soda-anthraquinone, organosolv and ethanol process lignins. Ind. Crops Prod. 24, 8-16 (2006)

29. Wang, S., et al.: Green modification of corn stalk lignin and preparation of environmentally friendly lignin-based wood adhesive. Polymers 10(6), 631 (2018)

30. Dias, O.A.T., et al.: Recent approaches and future trends for lignin-based materials. Mol. Cryst. Liq. Cryst. 655(1), 204-223 (2017)

31. Thakur, V.K., et al.: Progress in green polymer composites from lignin for multifunctional applications: a review. ACS Sustain. Chem. Eng. 2(5), 1072-1092 (2014)
32. Duval, A., Lawoko, M.: A review on lignin-based polymeric, micro- and nano-structured materials. React. Funct. Polym. 85(SI), 78-96 (2014)

33. Baker, D.A., Rials, T.G.: Recent advances in low-cost carbon fiber manufacture from lignin. J. Appl. Polym. Sci. 130(2), 713-728 (2013)

34. Baker, F.S. et al.: FY 2008 progress report: a low-cost carbon fibers from renewable resources. https://www.energy.gov/sites/prod/ files/2014/04/f14/7_low-cost_carbon_fiber_0.pdf (2008)

35. Sha, Y., et al.: Laser induced graphitization of PAN-based carbon fibers. RSC Adv. 8(21), 11543-11550 (2018)

36. Souto, F., et al.: Lignin-based carbon fiber: a current overview. Mater. Res. Express 5(7), 072001 (2018)

37. Suhas, P.J.M., et al.: Lignin-from natural adsorbent to activated carbon: a review. Biores. Technol. 98(12), 2301-2312 (2007)

38. Song, M., et al.: The preparation and performance of lignin-based activated carbon fiber adsorbents for treating gaseous streams. Front. Chem. Sci. Eng. 11(3), 328-337 (2017)

39. Sahoo, S., et al.: Characterization of industrial lignins for their utilization in future value added applications. Biomass Bioenerg 35(10), 4230-4237 (2011)

40. Hosseinpourpia, R., et al.: Modification of pea starch and dextrin polymers with isocyanate functional groups. Polymers 10(9), 939 (2018)

41. Hosseinpourpia, R., et al.: Utilization of different--tall oils for improving the water resistance of cellulosic fibers. J. Appl. Polym. Sci. 1(1), 47303 (2018)

42. Hosseinpourpia, R., et al.: Dynamic vapour sorption of wood and holocellulose modified with thermosetting resins. Wood Sci. Technol. 50(1), 165-178 (2016)

43. Yang, D., et al.: Structure and properties of sodium lignosulfonate with different molecular weight used as dye dispersant. J. Dispers. Sci. Technol. 36(4), 532-539 (2015)

44. Ziomek, E., Williams, R.E.: Modification of lignins by growing cells of the sulfate-reducing anaerobe Desulfovibrio desulfuricans. Appl. Environ. Microbiol. 9, 2262-2266 (1989)

45. Ouyang, X., et al.: Sulfonation of alkali lignin and its potential use in dispersant for cement. J. Dispers. Sci. Technol. 30(1), 1-6 (2009)

46. $\mathrm{Pu}, \mathrm{Y}$., et al.: Plant biomass characterization: application of solution- and solid-state NMR spectroscopy. Aqueous Pretreatment of Plant Biomass for Biological and Chemical Conversion to Fuels and Chemicals. (2013). https://doi.org/10.1002/9780470975831. ch18

47. Dababi, I., et al.: Organosolv lignin-based wood adhesive. Influence of the lignin extraction conditions on the adhesive performance. Polymers 8(9), 340 (2016)

48. Wen, J.-L., et al.: Recent advances in characterization of lignin polymer by solution-state Nuclear Magnetic Resonance (NMR) methodology. Materials 6(1), 359-391 (2013)

49. Run-Cang, S., et al.: Recent advances in characterization of lignin polymer by solution-state Nuclear Magnetic Resonance (NMR) methodology. Materials 6(1), 359-391 (2013)

50. Boeriu, C.G., et al.: Characterisation of structure-dependent functional properties of lignin with infrared spectroscopy. Ind Crops Prod 20(2), 205-218 (2004)

51. Casas, A., et al.: FTIR analysis of lignin regenerated from Pinus radiata and Eucalyptus globulus woods dissolved in imidazoliumbased ionic liquids. J. Chem. Technol. Biotechnol. 87(4), 472-480 (2012)

52. Obst, J.R., Laaducci, L.L.: The syringyl content of softwood lignin. J. Wood Chem. Technol. 6(3), 311-327 (1986)

53. El Mansouri, N.-E., et al.: Study of chemical modification of alkaline lignin by the glyoxalation reaction. BioResources 6(4), 4523-4536 (2011) 
54. Mohamad Ibrahim, M.N., et al.: Chemical and thermal properties of lignins from oil palm biomass as a substitute for phenol in a phenol formaldehyde resin production. Carbohyd. Polym. 86(1), 112-119 (2011)

55. Faix, O.: Classification of lignins from different botanical origins by FT-IR spectroscopy. Holzforschung 45, 21-28 (1991)

56. El Mansouri, N.-E., Salvadó, J.: Analytical methods for determining functional groups in various technical lignins. Ind. Crops Prod. 26(2), 116-124 (2007)

57. Liu, Y., et al.: Study on biodegradation process of lignin by FTIR and DSC. Environ. Sci. Pollut. Res. 21(24), 14004-14013 (2014)

58. Chupin, L., et al.: Study of thermal durability properties of tannin-lignosulfonate adhesives. J. Therm. Anal. Calorim. 119(3), 1577-1585 (2015)

59. Wörmeyer, K., et al.: Comparison of different pretreatment methods for lignocellulosic materials. Part II: influence of pretreatment on the properties of rye straw lignin. Biores. Technol. 102(5), 4157-4164 (2011)

60. Ghorbani, M., et al.: Commercial lignosulfonates from different sulfite processes as partial phenol replacement in PF resole resins. J. Appl. Polym. Sci. 135(8), 45893 (2018)

61. Carrier, M., et al.: Thermogravimetric analysis as a new method to determine the lignocellulosic composition of biomass. Biomass Bioenerg. 35(1), 298-307 (2011)

62. Tejado, A., et al.: Physico-chemical characterization of lignins from different sources for use in phenol-formaldehyde resin synthesis. Biores. Technol. 98(8), 1655-1663 (2007)

63. Younesi-Kordkheili, H., Pizzi, A.: A comparison between lignin modified by ionic liquids and glyoxalated lignin as modifiers of urea-formaldehyde resin. J. Adhes. 93(14), 1120-1130 (2017)

64. Fox, S.C., McDonald, A.G.: Chemical and thermal characterization of three industrial lignins and their corresponding lignin esters. BioResources 5(2), 990-1009 (2010)
65. Youssefian, S., et al.: Variation of nanostructures, molecular interactions, and anisotropic elastic moduli of lignocellulosic cell walls with moisture. Sci. Rep. 7(1), 1 (2017)

66. Chirkova, J., et al.: Study of the structure of wood-related biopolymers by sorption methods. BioResources 4(3), 1044-1057 (2009)

67. Volkova, N., et al.: Water sorption isotherms of Kraft lignin and its composites. Carbohyd. Polym. 87(2), 1817-1821 (2012)

68. Hosseinpourpia, R., et al.: Effects of acid pre-treatments on the swelling and vapor sorption of thermally modified Scots pine (Pinus sylvestris L.) wood. BioResources 13(1), 331-345 (2018)

69. Hess, K., et al.: Nanoscale hygromechanical behavior of lignin. Cellulose 25(11), 6345-6360 (2018)

70. Faruk, O. and Sain, M., Lignin reinforcement in thermoplastic composites. In: Lignin in polymer composites. William Andrew Publishing, Norwich, pp. 95-118 (2016).

71. Qian, Y., et al.: Solution behaviors and adsorption characteristics of sodium lignosulfonate under different $\mathrm{pH}$ conditions. BioResources 6(4), 4686-4695 (2011)

72. Yang, D., et al.: Properties of sodium lignosulfonate as dispersant of coal water slurry. Energy Convers. Manag. 48(9), 2433-2438 (2007)

73. Yang, S., et al.: Preparation of lignin-phenol-formaldehyde resin adhesive based on active sites of technical lignin. J. Biobased Mater. Bioenergy 9, 266-272 (2015)

74. Zhang, M., Ogale, A.A.: Carbon fibers from dry-spinning of acetylated softwood kraft lignin. Carbon 69(C), 626-629 (2014)

Publisher's Note Springer Nature remains neutral with regard to jurisdictional claims in published maps and institutional affiliations.

\section{Affiliations}

\section{Venla Hemmilä ${ }^{1}\left[\right.$ - Reza Hosseinpourpia ${ }^{1}$ - Stergios Adamopoulos ${ }^{1} \cdot$ Arantxa Eceiza $^{2}$}

Stergios Adamopoulos

stergios.adamopoulos@lnu.se

1 Department of Forestry and Wood Technology, Linnaeus University, Lückligs plats 1, 35195 Växjö, Sweden
Materials \& Technologies' Group, Department of Chemical \& Environmental Engineering, Faculty of Engineering of Gipuzkoa, University of the Basque Country UPV/EHU, Pza. Europa 1, 20018 Donostia-San Sebastián, Spain 